\title{
Design of a New Outer-Rotor Permanent Magnet Hybrid Machine for Wind Power Generation
}

\author{
Chunhua Liu ${ }^{1}$, K. T. Chau ${ }^{1}$, J. Z. Jiang ${ }^{2}$, and Linni Jian ${ }^{1}$ \\ ${ }^{1}$ Department of Electrical and Electronic Engineering, The University of Hong Kong, Hong Kong, China \\ ${ }^{2}$ Department of Automation, Shanghai University, Shanghai 200072, China
}

\begin{abstract}
This paper proposes and implements a new 36/24-pole outer-rotor permanent magnet (PM) hybrid machine for directly coupled wind power generation. The key is to design the machine with hybridization of two excitations (PMs and de field windings) in the double-layer stator so that it can provide effective flux control, hence realizing constant voltage output over wide ranges of speeds and loads. The machine design is illustrated by finite-element analysis and then verified by experimentation.
\end{abstract}

Index Terms-Finite-element method (FEM), hybrid machine, permanent magnet (PM) machine, wind power generation.

\section{INTRODUCTION}

W ITH ever-increasing interest in renewable energy resources, the development of wind power generation is accelerating. Permanent magnet (PM) machines have been widely accepted for wind power generation, because they have the definite advantages of high efficiency and high power density [1], [2]. Their outer-rotor topology is particularly attractive, since it facilitates direct coupling with the wind blades [3]. However, all these PM machines suffer from the problem of uncontrollable flux. Recently, the concept of PM hybrid machine has been proposed to provide flux control [4]. However, the corresponding hybridization is very bulky, which severely deteriorates its power density.

In this paper, a new outer-rotor PM hybrid machine is proposed for wind power generation. Different from other PM hybrid machines, the proposed machine artfully integrates two excitations (PMs and field windings) in the inner stator so that the overall size and weight are significantly reduced. Hence, this machine not only allows for direct coupling with the wind blades, but also provides constant voltage output over wide ranges of wind speeds and loads. Since the machine has a special configuration, the time-stepping finite-element method (FEM) [5] will be employed to analyze the characteristics of the proposed machine. A $2-\mathrm{kW}$ prototype is constructed. Hence, the proposed machine will be verified by comparing simulation results with experimental results.

\section{Machine Design AND ANALYsis}

The configuration of the proposed PM hybrid machine is shown in Fig. 1, which incorporates an outer rotor and a double-layer stator. The outer rotor simply consists of 24 salient poles, and has neither windings nor PMs. Hence, it is very robust and can directly couple with the wind blades. The novelty of the double-layer stator is to provide a compact hybridization of two excitations (PMs and dc field windings). Namely, the outer stator has 36 salient poles with three-phase $\mathrm{AC}$ armature windings, while the inner stator has both PMs and

Digital Object Identifier 10.1109/TMAG.2007.916503

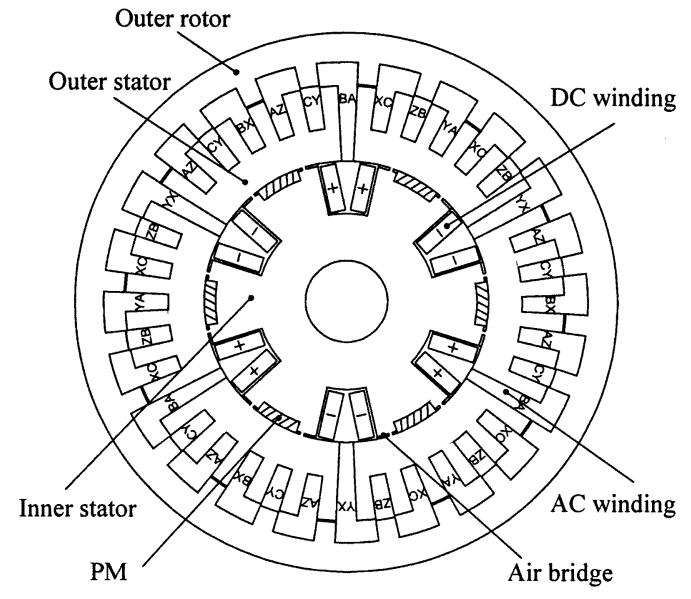

Fig. 1. Machine configuration.

dc field windings to produce two excitations. Moreover, an air bridge is also created to shunt with each PM so that the effect of flux weakening can be significantly amplified. Therefore, by simply tuning the dc field current, the proposed machine can maintain a constant voltage output over a wide range of wind speeds (from $1 / 3$ to 3 times the based speed).

The relationships of the number of rotor poles, the stator poles and the dc field winding pole pairs are governed by $N_{s}=4 m p$ and $N_{r}=2 N_{s} / m$, where $N_{s}$ is the number of stator poles, $N_{r}$ the number of rotor poles, $p$ the number of pole pairs of the dc field windings, and $m$ the number of phases. The larger the value of $p$, the bigger the number of $N_{r}$ is resulted, which will increase the operating frequency and hence the iron loss. On the contrary, if $p$ is too small, the low operating frequency will cause difficulty in smoothing the rectified output voltage. Thus, the proposed machine adopts $m=3$ and $p=3$, hence having $N_{s}=36$ and $N_{r}=24$.

The proposed machine configuration possesses several advantages. First, the outer-rotor topology enables the rotor directly coupling with the wind blades, which can eliminate complicated mechanical transmission. Second, since this rotor has neither PMs nor field windings, it can provide high mechanical integrity which is essential to handle those intermittently strong winds. Third, since both the PMs and dc field windings can fully 


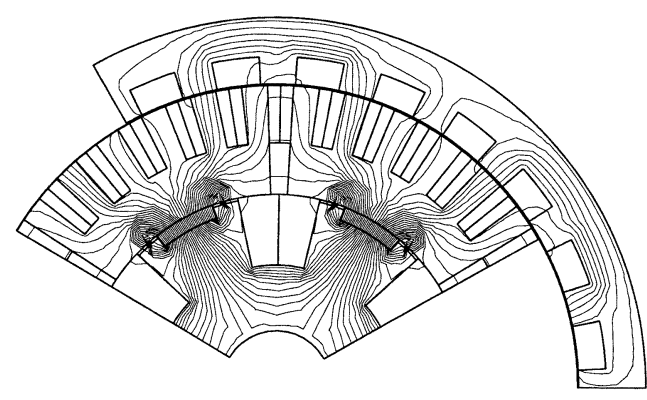

(a)

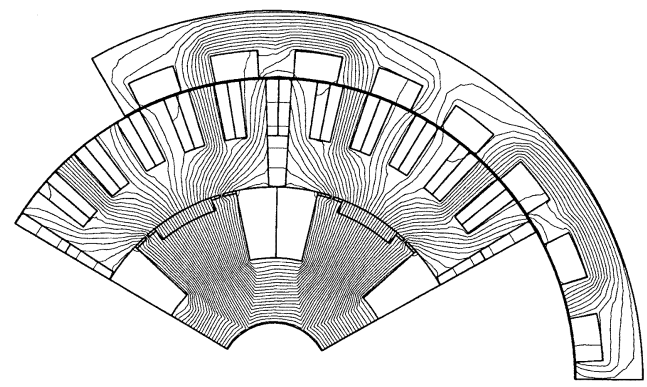

(b)

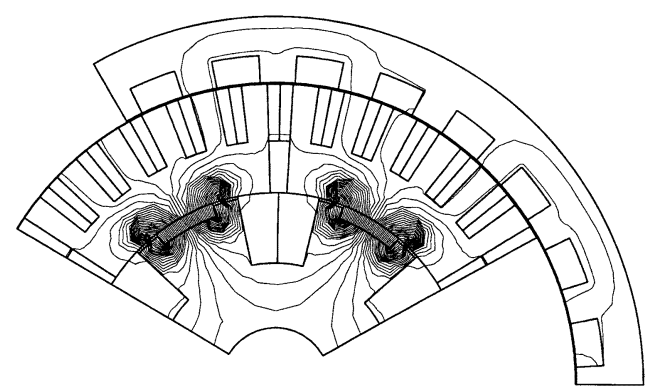

(c)

Fig. 2. Magnetic field distributions under different field currents. (a) $F_{\mathrm{dc}}=0$ A-turns. (b) $F_{\mathrm{dc}}=1000$ A-turns. (c) $F_{\mathrm{dc}}=-350$ A-turns.

utilize the space of inner stator, the flux leakage can be minimized while the power density can be improved.

Although the use of dc field windings in the proposed machine causes additional power loss and hence reduces the overall efficiency, it can uniquely offer the feature of efficiency optimization for variable wind speeds. This efficiency optimization can partially compensate the power loss, or even outweigh the loss at certain wind speeds. On the other hand, the material cost of the proposed machine is generally lower than that of the traditional PM machine, since the use of dc field windings can reduce the requirement of PM material which is most expensive. Moreover, compared with the traditional one, the proposed machine is less dependent on power electronics, which is due to its feature of constant voltage output. It should be noted that the additional dc-dc converter for field current control has much lower ratings and hence lower cost than the removed dc-dc converter for output voltage control.

Fig. 2 shows the no-load magnetic field distributions under no flux control $\left(F_{\mathrm{dc}}=0\right)$, flux strengthening $\left(F_{\mathrm{dc}}=1000\right.$ A-turns) and flux weakening ( $F_{\mathrm{dc}}=-350$ A-turns), respectively. It illustrates that with bidirectional dc field current regulation, the magnetic field can be effectively controlled. The corresponding radial airgap flux density distributions are also shown

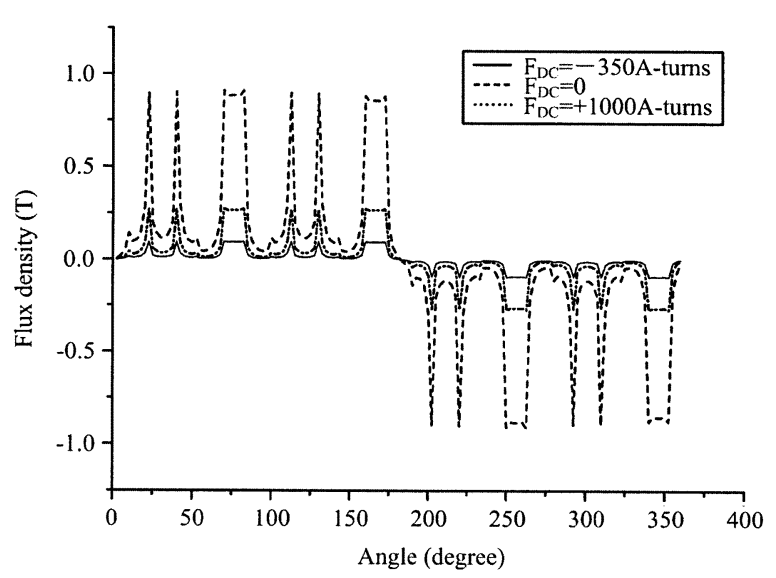

Fig. 3. Airgap flux density distributions under different field currents.

TABLE I

KEY DESIGN DATA

\begin{tabular}{ll}
\hline \hline Rated power & $2 \mathrm{~kW}$ \\
Rated voltage & $220 \mathrm{~V}$ \\
Number of phases & 3 \\
Number of stator poles & 36 \\
Number of rotor poles & 24 \\
Number of turns per armature coil & 46 \\
Number of turns per field coil & 150 \\
Rotor outside diameter & $270.0 \mathrm{~mm}$ \\
Rotor inside diameter & $221.2 \mathrm{~mm}$ \\
Stator outside diameter & $220.0 \mathrm{~mm}$ \\
Airgap length & $0.6 \mathrm{~mm}$ \\
Air bridge length & $1.0 \mathrm{~mm}$ \\
Stack length & $80 \mathrm{~mm}$ \\
PM material & $38 \mathrm{SH} \mathrm{Nd}-\mathrm{Fe}-\mathrm{B}$ \\
\hline \hline
\end{tabular}

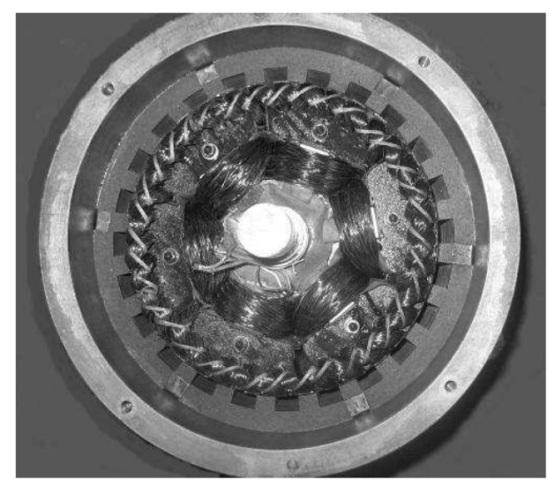

Fig. 4. Machine prototype.

in Fig. 3. It can be found that the airgap flux can be flexibly regulated over a range of 9 times. Hence, by properly tuning the dc field current, the output voltage can be maintained constant at different wind speeds and load currents.

\section{RESULTS AND VERIFICATION}

The proposed PM hybrid machine is purposely designed as a wind power generator. The corresponding key data is listed in Table I. As shown in Fig. 4, a 2-kW prototype is built for experimentation.

First, in order to assess the dynamic performance of the proposed flux control, the machine runs from standstill to $1200 \mathrm{rpm}$ 


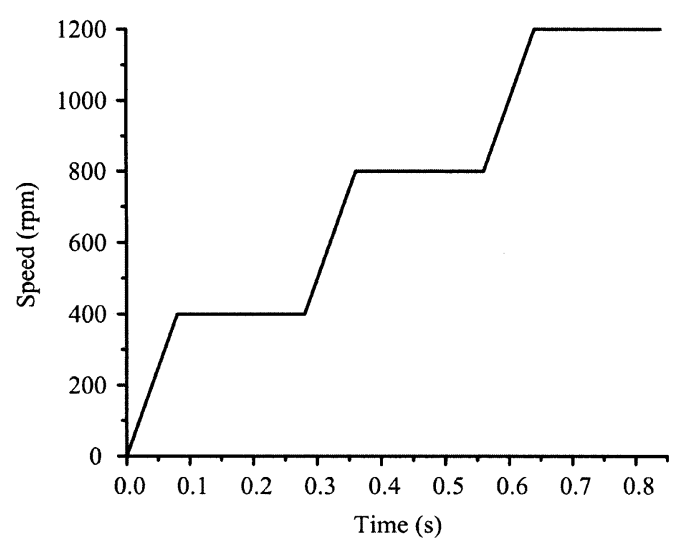

(a)

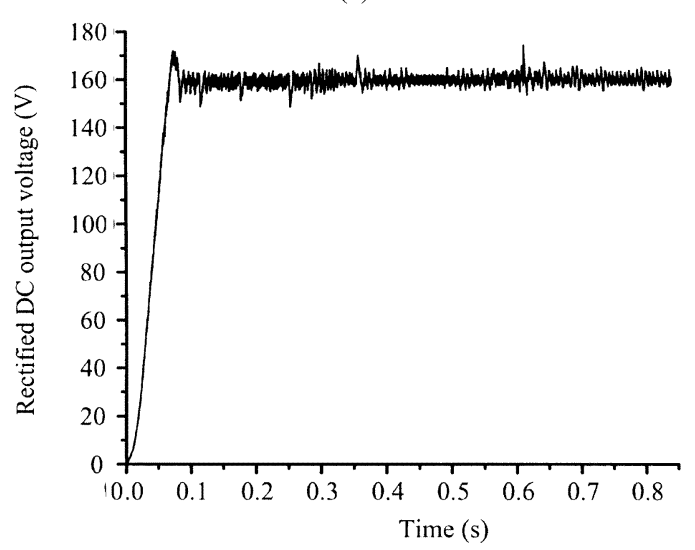

(b)

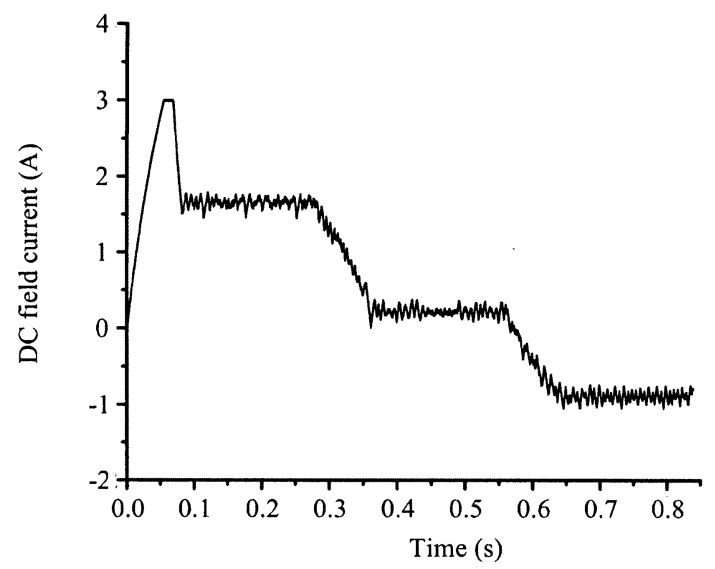

(c)

Fig. 5. Transient responses under flux control. (a) Speed. (b) Rectified dc output voltage. (c) DC field current.

with a step of $400 \mathrm{rpm}$ in such a way that the output voltage should be maintained constant based on online flux control. By using the time-stepping FEM, the transient responses of rotor speed, rectified dc output voltage and dc field current are shown in Fig. 5. It can be seen that through online flux control, the output voltage can be maintained constant with good dynamic performance.

Second, the steady-state performance is assessed. Fig. 6 shows the simulated no-load EMF waveforms at 100, 300, and $900 \mathrm{rpm}$ without and with flux control. As expected, the voltage amplitudes vary with speeds under no flux control, whereas

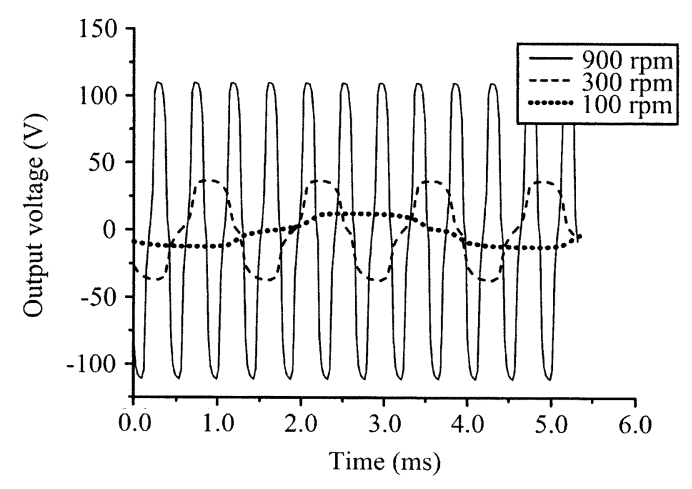

(a)

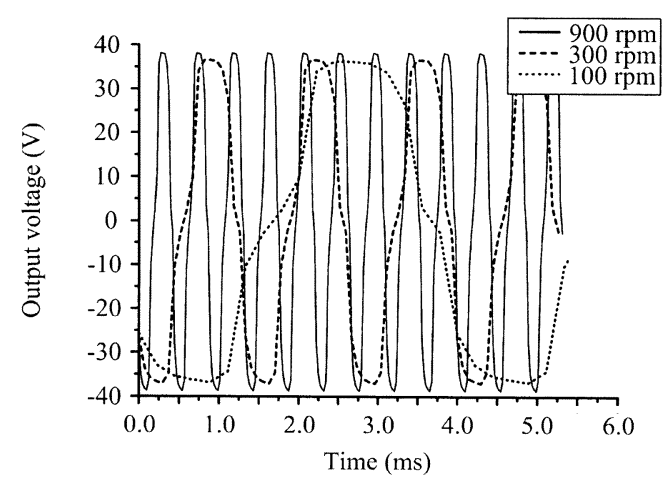

(b)

Fig. 6. Simulated no-load EMF waveforms at various speeds. (a) Without flux control. (b) With flux control.

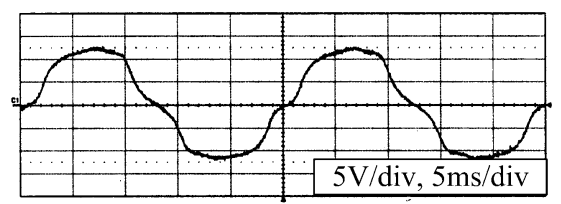

(a)

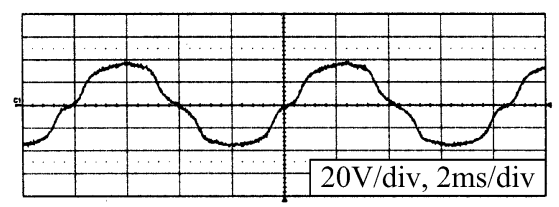

(b)

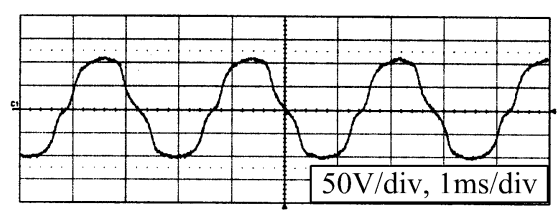

(c)

Fig. 7. Measured no-load EMF waveforms at various speeds without flux control. (a) $100 \mathrm{rpm}$. (b) $300 \mathrm{rpm}$. (c) $900 \mathrm{rpm}$.

they can keep constant over those speeds under proper flux control. The corresponding measured waveforms are shown in Figs. 7 and 8, hence verifying the results obtained from using the time-stepping FEM. Furthermore, the characteristics of dc field current control for constant voltage output are summarized as shown in Fig. 9. It can be seen that the experimental characteristic agrees well with the simulated one. Nevertheless, there are some discrepancies between them, which are mainly 


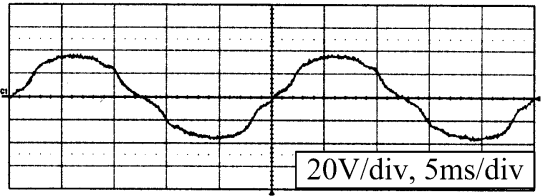

(a)

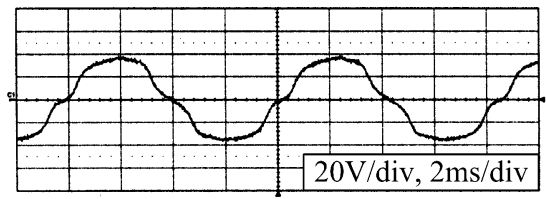

(b)

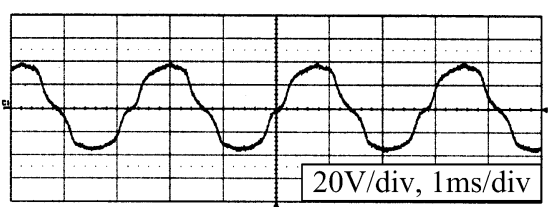

(c)

Fig. 8. Measured no-load EMF waveforms at various speeds with flux control. (a) $100 \mathrm{rpm}$. (b) $300 \mathrm{rpm}$. (c) $900 \mathrm{rpm}$.

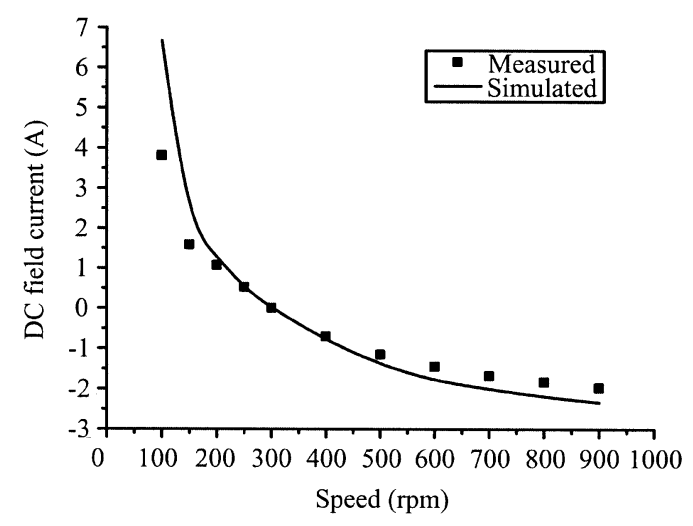

Fig. 9. Field current control for constant voltage output.

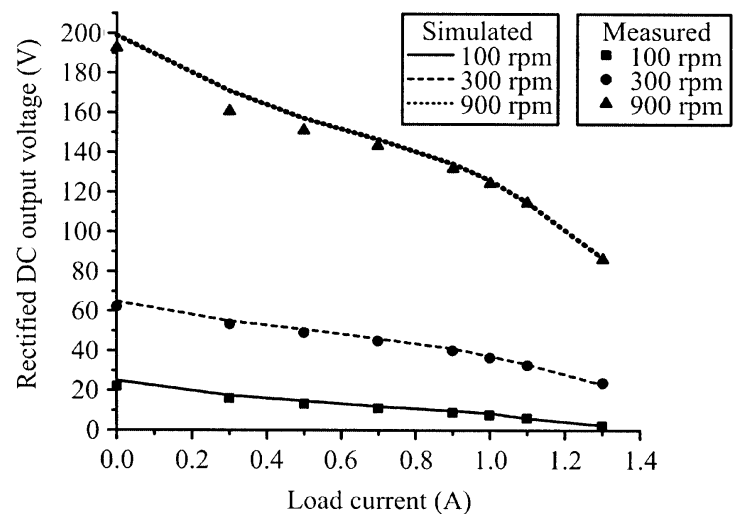

Fig. 10. Rectified dc output voltage characteristics at various speeds without flux control.

due to the manufacturing imperfection, control nonideality, and measurement error.

Third, Fig. 10 shows the simulated and measured characteristics of the rectified dc output voltages versus load currents

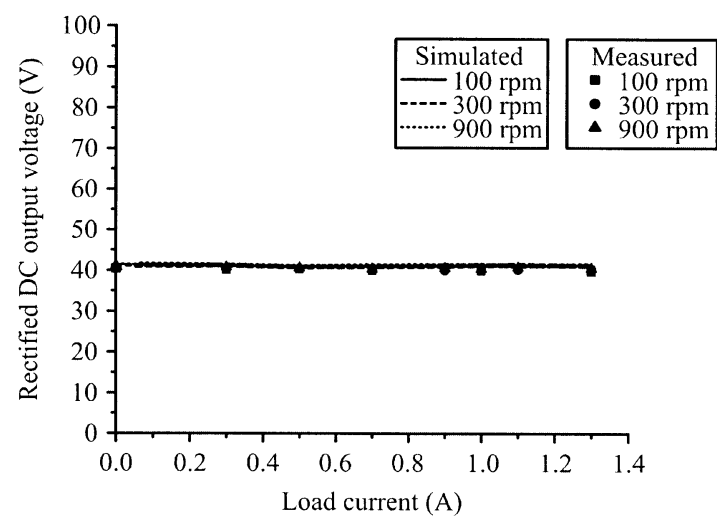

Fig. 11. Rectified dc output voltage characteristics at various speeds with flux control.

without flux control. They both confirm that the output voltage drops with the increase of load currents. Then, this voltage drop can be successfully compensated by using flux control as illustrated in Fig. 11

Therefore, it can be confirmed that the proposed machine can generate constant output voltage even under wide ranges of rotor speeds and load currents.

\section{CONCLUSION}

In this paper, a new outer-rotor PM hybrid machine has been designed and implemented for wind power generation. The proposed machine possesses a unique double-layer stator structure which can offer effective flux control, hence maintaining constant voltage output over wide ranges of wind speeds and load currents. Also, the outer-rotor structure enables the machine direct coupling with the wind blades. Both simulation and experimental results have been given to verify the validity of the proposed machine.

\section{ACKNOWLEDMENTS}

This work was supported and funded by a Grant (HKU 7111/ 05E) from the Research Grants Council, Hong Kong Special Administrative Region, China.

\section{REFERENCES}

[1] Y. Fan, K. T. Chau, and M. Cheng, "A new three-phase doubly salient permanent magnet machine for wind power generation," IEEE Trans. Ind. Appl., vol. 42, no. 1, pp. 53-60, 2006.

[2] Y. Chen, P. Pillay, and A. Khan, "PM wind generator topologies," IEEE Trans. Ind. Appl., vol. 41, no. 6, pp. 1619-1626, 2005.

[3] J. Chen, C. V. Nayar, and L. Xu, "Design and finite-element analysis of an outer-rotor permanent-magnet generator for directly coupled wind turbines," IEEE Trans. Magn., vol. 36, no. 5, pp. 3802-3809, 2000.

[4] K. T. Chau, Y. B. Li, J. Z. Jiang, and S. Niu, "Design and control of a PM brushless hybrid generator for wind power application," IEEE Trans. Magn., vol. 42, no. 10, pp. 3497-3499, 2006.

[5] Y. Wang, K. T. Chau, C. C. Chan, and J. Z. Jiang, "Transient analysis of a new outer-rotor permanent-magnet brushless dc drive using circuitfield-torque time-stepping finite element method," IEEE Trans. Magn. vol. 38, no. 2, pp. 1297-1300, 2002.

Manuscript received June 24, 2007. Corresponding author: C. Liu (e-mail: chualiu@eee.hku.hk). 